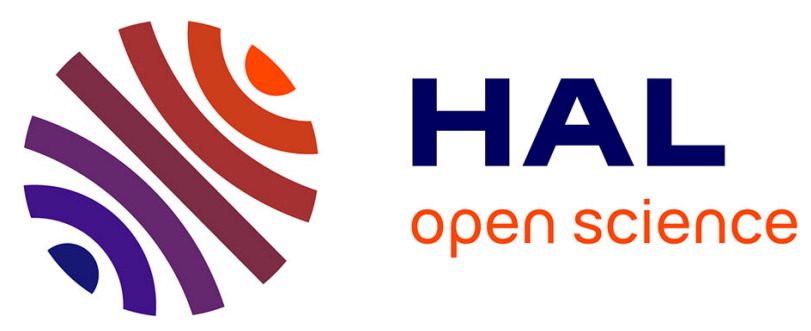

\title{
Weight Evolution During Endocrine Therapy for Breast Cancer in Postmenopausal Patients: Effect of Initial Fat Mass Percentage and Previous Adjuvant Treatments
}

\author{
Angeline Ginzac, Emilie E. Thivat, Marie-Ange Mouret-Reynier, Pascale
} Dubray-Longeras, Isabelle van Praagh, Judith Passildas, Catherine Abrial, Fabrice Kwiatkowski, Yves Y. Boirie, Martine Duclos, et al.

\section{To cite this version:}

Angeline Ginzac, Emilie E. Thivat, Marie-Ange Mouret-Reynier, Pascale Dubray-Longeras, Isabelle van Praagh, et al.. Weight Evolution During Endocrine Therapy for Breast Cancer in Postmenopausal Patients: Effect of Initial Fat Mass Percentage and Previous Adjuvant Treatments. Clinical Breast Cancer, 2018, 18 (5), pp.1091-1100. 10.1016/j.clbc.2018.06.010 . hal-01834391

\author{
HAL Id: hal-01834391 \\ https://hal.science/hal-01834391
}

Submitted on 8 Nov 2019

HAL is a multi-disciplinary open access archive for the deposit and dissemination of scientific research documents, whether they are published or not. The documents may come from teaching and research institutions in France or abroad, or from public or private research centers.
L'archive ouverte pluridisciplinaire HAL, est destinée au dépôt et à la diffusion de documents scientifiques de niveau recherche, publiés ou non, émanant des établissements d'enseignement et de recherche français ou étrangers, des laboratoires publics ou privés. 


\section{Weight evolution during endocrine therapy for breast cancer in postmenopausal patients: impact of initial fat mass percentage and previous adjuvant treatments}

Ginzac Angeline1, Thivat Émilie ${ }^{1}$, Mouret-Reynier Marie-Ange ${ }^{1}$, Dubray-Longeras Pascale $^{2}$, Van Praagh Isabelle ${ }^{2}$, Passildas Judith ${ }^{1}$, Abrial Catherine ${ }^{1}$, Kwiatkowski Fabrice $^{1}$, Yves Boirie ${ }^{3}$, Martine Duclos ${ }^{3,4}$, Béatrice Morio ${ }^{5}$, Émilie Gadea ${ }^{6}$, Durando Xavier $^{1}$

1. Université Clermont Auvergne, Centre Jean Perrin, INSERM, U1240 Imagerie Moléculaire et Stratégies Théranostiques, F-63000 Clermont Ferrand, France

2. Centre Jean Perrin, FR-63000 Clermont-Ferrand, France

3. INRA, UMR 1019, UNH, CRNH Auvergne, Clermont-Ferrand, FR-63000, France

4. CHU Clermont-Ferrand, Service de Médecine du Sport et des Explorations Fonctionnelles, CRNH, INRA, Université Clermont Auvergne, Clermont-Ferrand, FR-63000, France

5. INRA, UMR 1397, Laboratoire CarMeN, Université Lyon 1, FR-69000, France

6. CH Emile Roux, FR-43000 le Puy en Velay, France

Corresponding author: Angeline GINZAC

Centre Jean Perrin

58, rue Montalembert - BP 392

63011 CLERMONT-FERRAND, FRANCE

Angeline.GINZAC@clermont.unicancer.fr

Key words: Postmenopausal breast cancer; adjuvant treatment; endocrine therapy; body composition; fat mass

This research did not receive any specific grant from funding agencies in the public, commercial, or not-for-profit sectors.

Declarations of interest: none 


\section{MICROABSTRACT}

Weight variations during treatment are associated with poor prognosis for early breast cancer patients. The study of body composition during adjuvant treatment is the key to understanding this interaction. With a median follow up of 3 years post-chemotherapy, our results show a small weight gain, but highlights that initial fatness in postmenopausal breast cancer patients promotes longitudinal 3-years weight gain.

\section{ABSTRACT}

Purpose: Weight change during adjuvant treatment for early breast cancer is associated with poor prognosis. The long-term evolution of body composition during adjuvant treatment for breast cancer, particularly endocrine therapy, is not well known and new data on this topic is required. The present study assesses the evolution of weight and body composition among 33 postmenopausal breast cancer patients currently treated with endocrine therapy after standard adjuvant chemotherapy including Taxanes.

Patients and Methods: Dual-Energy X-ray Absorptiometry (DXA) was used to measure fat and lean body mass. Body water was assessed by multifrequency bioelectrical impedance analysis. The HAD questionnaire and the short version of the IPAQ were also administered. Results: During endocrine therapy, $15.2 \%(n=5)$ of the population lost weight and $36.4 \%$ $(n=12)$ gained weight. The overall average gain was $2.0 \mathrm{~kg} \pm 5.5(p=0.04)$. During this period, fat mass, lean body mass and body water increased. Factors linked to fat mass gain are excess fat mass $(\geq 36 \%)$ before treatment and weight loss during chemotherapy. In the overall period of adjuvant cancer treatment, $30 \%$ of the population gained more than $5 \%$ of their initial weight. The average gain was the same as during the endocrine therapy period $(2.0 \mathrm{~kg} \pm 5.4 ; p=0.031)$ and was characterized by an increase in total lean body mass, mainly localized in the trunk region.

Conclusion: Endocrine therapy appears as a pivotal period in weight and body composition management. Overfat/obese patients and those who lose weight during chemotherapy are more subject to weight and fat mass gain during endocrine therapy. 


\section{INTRODUCTION}

Excess weight is well known to be a risk factor in breast cancer ${ }^{1,2}$ and at the time of diagnosis is considered as a poor prognosis factor, with higher risks of recurrence and mortality ${ }^{3,4}$. There is also substantial evidence that weight change during cancer treatment could be associated with poorer prognosis among women with early breast cancer, whether weight gain or weight loss ${ }^{3,5}$.

Mechanisms to explain the adverse effect of weight variation have not been clearly identified but two hypotheses have been proposed ${ }^{6}$ : (i) adipose tissue is a source of oestrogen production and becomes the main source of oestrogen after the menopause, so a higher circulating oestrogen level associated with abdominal obesity is observed ${ }^{7}$, especially in oestrogen-dependent postmenopausal cancer ${ }^{1,3,8}$ and (ii) adipose tissue induces metabolic disturbances in the insulin and adipokine pathways.

As fat mass gain is the first hypothesis explaining the pejorative impact of weight gain, the evaluation of body composition is more appropriate than weight assessment. Weight and body composition variations among postmenopausal breast cancer patients have mainly been studied during chemotherapy. Water retention is one of the side effects of modern chemotherapy, particularly Taxane-based chemotherapy, ${ }^{9,10}$ and it is also thought that weight gain during chemotherapy results from greater water gain than fat mass gain (NCT01506466, under submission). These results could explain the absence of relationship between weight gain and poor prognosis shown by recent studies ${ }^{11,12}$.

While several studies found that a fairly small weight gain occurred during endocrine therapy ${ }^{13-16}$, a recent retrospective chart review ${ }^{17}$ shows that postmenopausal breast cancer survivors do not necessarily gain weight after two years of endocrine therapy. But little information is available about the impact of subsequent adjuvant treatment, among which endocrine therapy, on long-term body composition. In a double-blind placebo-controlled study with 24 months follow-up, an increase in lean body mass was observed among patients on aromatase inhibitors (Al) compared to those not treated with $\mathrm{Al}^{13}$. In the same way, a randomized trial showed that a switch from tamoxifen to Exemestane induced body composition modification in overweight or obese patients, with a decrease in fat mass and an increase in the fat-free mass/fat mass ratio in the group of patients receiving $\mathrm{Al}$, compared to the continued tamoxifen group ${ }^{18,19}$. In another study, after at least 6 months of Al, the total abdominal adipose tissue increase was about $9,1 \%$ in all subjects whatever the weight variation, reflecting an increase in the volume of visceral abdominal tissue ${ }^{20}$. This study highlights the importance of studying body composition, because weight variations do not reflect body mass distribution. 
Body composition variation seems to differ markedly according to the type of treatment (chemotherapy, hormonotherapy) and for patients treated with both we do not know the impact of previous variations in weight and body composition under chemotherapy on variation during hormonotherapy.

To the best of our knowledge, no longitudinal study of body composition has been conducted on a cohort of early breast cancer patients treated with adjuvant chemotherapy, radiotherapy and then endocrine therapy. The aim of this study was to characterize the evolution in weight and body composition of postmenopausal breast cancer patients treated with adjuvant endocrine therapy (for more than one year) after chemotherapy. Factors influencing to these parameters during endocrine treatment, will also been investigated.

\section{PATIENTS AND METHODS}

\section{Study population}

From July 2015 to November 2016, 33 patients were enrolled in the MetaCa2 trial (NCT02509871) (see Figure 1). This study was approved by competent authority and the local ethics committee. All participants signed informed consent. All of them had participated in the previous MetaCa trial (NCT01506466) which investigated the evolution of body composition and related factors 1 month (T1) and 6 months (T2) after chemotherapy treatment (results under submission). Patients were invited to participate in the Metaca2 study only if they were currently receiving endocrine therapy. All patients were postmenopausal, and patients with a cancer relapse or another cancer were excluded.

\section{Study outcomes}

Data obtained in the Metaca study (T0-T1-T2) for the patients participating in the Metaca2 study were used for the longitudinal comparison of weight, body composition, anxiety/depression and time spent sitting. All measurements in the Metaca2 study were performed during a follow-up visit after a median time of three years following initiation of endocrine therapy $[1,8 ; 4,5]$ (T3; see Figure 2 : study design). The parameters were assessed according to the same methods as in the MetaCa study (NCT01506466; under submission).

\section{Body weight}

Body weight was measured to the nearest $0.1 \mathrm{~kg}$ in underwear and without shoes. The National Cancer Institute (CTCAE v.4.0) defines weight variation as a gain or loss greater than $5 \%$ of initial weight.

Body composition 
Dual-Energy X-ray Absorptiometry (DXA) (Hologic 94 Discovery QDR; Hologic Inc, Waltham, Massachusetts) was used to measure fat mass and lean body mass and their distribution. $A$ multifrequency bioelectrical impedance analysis (Bodystat Quadscan 4000) was used to evaluate total body water. To assess central fat distribution, waist circumference was measured to the nearest $0.5 \mathrm{~cm}$ with a standard tape measure placed between the lowest rib and the iliac crest, in standing position. In the same way, hip circumference was measured using standard tape placed horizontally on the widest point on the hip.

\section{Physical activity}

The short version of the International Physical Activity Questionnaire (IPAQ) was completed to evaluate time spent sitting per day in minutes and physical activity expressed in metabolic equivalent $(\mathrm{MET}) \times$ minutes per week ${ }^{21}$.

\section{Anxiety and depression}

Two validated self-administered questionnaires were used to evaluate anxiety and depression (Hospital Anxiety and Depression scale - HADs). The interpretation of this scale is based on the score: 7 or less means non-case, between 8 and 10 corresponds to a doubtful case and more than 11 reflects a definite case ${ }^{22}$.

\section{Statistical analyses}

SEM software was used to perform data-management and statistical calculations ${ }^{23}$. Patient characteristics were described using mean \pm standard deviation or median and [range] in case of non-Gaussian distribution, for quantitative parameters. For categorical parameters, counts and frequencies were calculated by category. The evolution of measures over time was tested using two-way ANOVA. Statistical relationships between pairs of variables where one variable was categorical were studied using Student's t-test, ANOVA (or Mann-Whitney U-test, Kruskal-Wallis H-test in case of non-Gaussian distributions and/or heteroscedasticity). When both variables were quantitative, Pearson's correlation coefficients (or Spearman rank correlations, if distributions were non-Gaussian) were calculated. All tests were two-sided and the standard significance threshold, $p \leq 0.05$, was used. Univariate analysis was performed using ANOVA to determine the parameters associated with weight and body composition variations (fat mass, lean body mass, body water). The parameters tested as potentially correlated with these variations between T2-T3 were age at diagnosis, age of menopause, medical history (arterial hypertension, smoking, hypothyroidism, lifetime weight variation, ongoing treatments, change in endocrine treatment), pre-adjuvant treatment factors (fat mass percentage, waist and hip circumference, $\mathrm{W} / \mathrm{H}$ ratio, android fat mass/gynoid fat mass ratio, lean body mass), variation of other parameters for each period of 
treatment (variation in weight, fat mass, and time spent sitting). Concerning T0-T3 variations, the same parameters were tested and body water variations for the different periods in the study were added.

Multivariate analysis using MANOVA was then performed, comprising all the factors selected in the previous univariate analysis $(p \leq 0.05)$.

We decided to divide our population into two groups according to the body fat ranges proposed by Gallagher and colleagues ${ }^{24}$, more precise than a classification by BMI, and taking into account the pre-chemotherapy fat mass value of patients from MetaCa study. (DXA, T0). We classified each patient in the normal fat mass subgroup (fat mass $<36 \%$ ) or the overfat/obese subgroup ( $\geq 36 \%$ fat mass), according to initial fat mass percentage and adjusting for the age.

\section{RESULTS}

\section{Patient characteristics}

Patient and treatment characteristics are summarized in Table 1. On the basis of the preadjuvant treatment fat mass percentage (T0), $48.4 \%$ of the population was classified as having normal fat mass, $36.4 \%(n=12)$ as overfat and $15.2 \%(n=5)$ as obese. At the T3 evaluation, the median duration of endocrine therapy was 3 years [1.8; 4.5]. The large majority of patients were currently treated with aromatase inhibitors (97\%). Only six patients had switched to a new endocrine treatment for reasons of tolerance: 2 from Tamoxifen to aromatase inhibitor and the others from one aromatase inhibitor to another.

\section{Weight variations}

\section{During endocrine therapy (Between T2 and T3)}

On average across the sample, a significant weight gain occurred after initiation of adjuvant antihormonal therapy $(+2.0 \mathrm{~kg} \pm 5.5)(p=0.04)$, i.e. between T2 and T3. Among these patients, $15.2 \%(n=5)$ lost weight $(-4.4 \mathrm{~kg} \pm 0.9$ i.e. $-7 \% \pm 1.4$ of their body weight $)$, and $36.4 \%(n=12)$ gained weight $(+8.3 \mathrm{~kg} \pm 3.6$ i.e. $12.1 \% \pm 7 \%)$. In relation to the pre-adjuvant cancer treatment fat mass percentage (TO), only the subgroup of overfat/obese patients underwent a significant weight change between T2 and T3 $\left(p<10^{-7}\right)$. In this subgroup, the average weight gain was $3.8 \mathrm{~kg}( \pm 5.6)(\mathrm{p}=0.012)$.

Univariate analyses showed that the weight gain between T2 and T3 depended on four factors: fat mass class $(p=0.014)$, waist $(p=0.043)$ and hip circumference $(p=0.016)$ at T0, 
and weight variation during chemotherapy $(p=0.0059)$. In multivariate analysis on these parameters, two still had a significant impact on the variation of weight between T2-T3. Firstly, weight variation during chemotherapy period $(p=0.000059)$ and secondly the initial fat mass class $(p=0.00052)$.

\section{For the overall period of treatment (between TO and T3)}

Over the full period of cancer treatment, from the pre-adjuvant cancer treatment (T0) to a median time of three years of endocrine therapy (T3), the average weight increase was about $2.0 \mathrm{~kg}( \pm 5.4)[-5.7 ; 22.2](\mathrm{p}=0.031)$ corresponding to a gain of $2.9 \%( \pm 7.9)$ compared to weight at T0. Nine percent $(n=3)$ of the population lost more than $5 \%$ of their pre-adjuvant treatment weight with an average loss of $5 \mathrm{~kg}( \pm 0.6)$, i.e. $8.3 \%( \pm 1.7)$. Thirty percent $(n=10)$ gained more than $5 \%$ of their initial weight with an average weight gain of $7.9 \mathrm{~kg}( \pm 5.9)$, i.e. $11.6 \%( \pm 8.4)$, and $61 \%$ remained stable $(n=20)$.

The longitudinal evolution of weight according to the pre-adjuvant treatment fat mass percentage is presented in Figure 3. Weight was not significantly impacted by the different periods of treatment from T0 to T3 (only a trend in the effect of time is observed $p=0.07$ ). The initial fat mass percentage was significantly related to the longitudinal evolution of weight $(p=0.033)$. In relation to initial fat mass percentage, while normal fat mass patients showed relative weight stability, overfat/obese patients lost weight during the chemotherapy period and then gained weight up to T3.

Several factors are associated with weight gain in the overall period of study (T0-T3), i.e. from pre-adjuvant treatment to a median time of three years after initiation of endocrine therapy. It was affected by age of menopause $(p=0.033)$, whereby women menopaused before the age of 52 gained more weight than those menopaused later. Weight gain greater than $5 \%$ between T2 and T3 $(\mathrm{p}=0.0003)$, increase in fat mass between and T2 and T3 $(p=0.031)$ and increase in body water between T2 and T3 $(p=0.034)$ were also significantly linked to weight gain between T0 and T3. Of these four significant parameters identified in the univariate analyses, three still retained significance in multivariate analyses. In descending order of probability, we find weight variation between T2 and T3 ( $p=0.0015)$, fat mass variation between T2 and T3 $(p=0.026)$, and age of menopause $(p=0.04)$. These three factors explain $41 \%$ of weight variation across the period of study (T0-T3).

\section{Body composition variations}

Changes in fat mass, lean body mass and body water 
Body composition changes are presented in Table 2. The variations during the period of endocrine therapy (T2-T3) are presented in Figure 4. For the overall population, a significant gain in total fat mass is observed $(1.8 \mathrm{~kg} \pm 3.8 ; p=0.0073)$ mainly localized in the abdominal region (1.4kg $\pm 2.2 ; p=0.00031$ ). A significant increase in both total and trunk lean body mass also occurred, corresponding to a gain in body water. No significant variations were observed in the subgroup of normal fat mass patients. Overfat/obese patients, for their part, saw an increase in their total and trunk fat mass of about $2.8 \mathrm{~kg}( \pm 3.5)(p=0.0054)$ and $2.2 \mathrm{~kg}( \pm 2)$ $(p=0.00067)$ respectively. They also gained total $(1.4 \mathrm{~kg} \pm 2.2 ; p=0.024)$ and trunk $(1.4 \pm 1,6$; $p=0.0048)$ lean body mass, corresponding to a gain in body water $(1.4 \mathrm{~kg} \pm 1.6 ; p=0.0052)$ at intracellular level (1.5 $\pm 2.6 ; p=0.047)$.

Fat mass gain between T2 and T3 was linked to the initial fat mass class ( $p=0.053)$, weight variation between T0 and T1 $(p=0.00031)$ and time spent sitting $(T 1-T 2)(p=0.05)$. All these parameters were still significant in multivariate analyses. These factors explain $44 \%$ of fat mass variation between T2 and T3, i.e. from six month post-chemotherapy to a median time of three years post initiation of endocrine therapy. Concerning body water variation between T2 and T3, when the parameters identified as significant in the univariate analyses (i.e. preadjuvant treatment fat mass class and weight variation between T0-T1) were tested in multivariate analyses, we did not find any variable implicated in the variation.

Over the whole period of treatment (T0-T3), body composition in the overall population $(n=33)$ is characterized by a significant increase in total lean body mass $(+1.5 \pm 3.2$; $p=0.0083)$ especially in the trunk region $(+0.85 \mathrm{~kg} \pm 2 ; p=0.015)$. These variations reflect the variation occurring in the subgroup of overfat/obese patients where a gain in total lean body mass $(2.1 \mathrm{~kg} \pm 3.7 ; p=0.034)$ and trunk lean body mass $(1,3 \mathrm{~kg} \pm 2.3 ; p=0.034)$ was observed. No variation in fat mass was observed in the overall population nor in the subgroups of patients.

Lean body mass variation between T0 and T3 was linked to age of menopause $(p=0.0084)$, initial fat mass percentage $(p=0.043)$, weight variation between T2-T3 ( $p=0.02)$, fat mass variation between T0-T1 ( $p=0.0 .035)$ and body water variation between T2-T3 ( $p=0.000076)$. Multivariate analyses revealed that four factors were significantly associated with lean body mass variation between T0-T3: weight variation between T2-T3 $(p=0.0009)$, age of menopause $(p=0.0026)$, body water variation between T2-T3 $(p=0.0067)$ and finally fat mass variation during the chemotherapy period (T0-T1) $(p=0.03)$. More than half of the lean body mass variation between T0 and T3 is explained by these factors (57\%).

\section{Changes in waist and hip circumference}


During the T2-T3 period, there was no significant difference in the waist to hip ratio $(\mathrm{W} / \mathrm{H}$ ratio) $(p=0.55)$, whether in the overall population or in the different subgroups. Nevertheless, during this period, significant increases in both waist and hip circumferences are observed for overfat/obese patients, respectively $+7.5 \mathrm{~cm} \pm 7.5(p=0.0017)$ and $+4.8 \pm 4.6(p=0.0012)$.

Overall, no significant change was observed in the evolution of the $\mathrm{W} / \mathrm{H}$ ratio. Nevertheless, the subgroup of overfat/obese patients had a $\mathrm{W} / \mathrm{H}$ ratio of over 0.85 , meaning android obesity, throughout the study (from T0 to T3). In the same way, from the beginning of the study to the last follow-up, their waist circumference was over $90 \mathrm{~cm}$, also characterising android obesity. Their waist circumference increased about $8.5 \mathrm{~cm}( \pm 7.8)(p=0.0013)$ between T0 and T3.

\section{Analysis of results on the short version of the IPAQ questionnaire}

Overall, time spent sitting increased by about 112 minutes $( \pm 154)$ on average from preadjuvant treatment (TO) to a median time of three years post initiation of endocrine therapy (T3) ( $p=0.00048)$. More precisely, between T2 (six month post chemotherapy) and T3, an increase of about 100.4 minutes $( \pm 166)(p=0.0042)$ was observed. Regarding subgroups, only overfat/obese patients exhibited significant variations in their time spent sitting in these two periods, i.e.T0-T3 and T2-T3. Nevertheless, in our population at T3 evaluation, 91\% $(n=30)$ of the patients reported more than 750 MET.min/week and only $6 \%$ reported less than 450 MET.min/week $(n=2)$.

\section{Analysis of the HAD questionnaire}

In the overall population, at T3, we found that $21.2 \%(n=7)$ of the patients had an anxiety score between 8 and 10 and $33.3 \%(n=11)$ had a score over 11 revealing a state of anxiety. Concerning the depression score, $85 \%(n=28)$ of the population had a score under the threshold and $6 \%(n=2)$ had a score reflecting depressive symptoms. However no significant changes in anxiety and depression levels were observed over the period of treatment.

\section{DISCUSSION}

This trial assessed the body composition evolution among postmenopausal breast cancer patients after a median time of three years of endocrine therapy post-chemotherapy, and studied factors implicated in variations observed.

After a median follow-up of 3 years of endocrine therapy (T2-T3), we found a mean weight gain of about $2.0 \mathrm{~kg}( \pm 5.5)$. This result is consistent with previous studies, which reported a weight gain under endocrine treatment of around $2 \mathrm{~kg}$. Baum and colleagues ${ }^{25}$ studied 
weight variations over 24 months in three groups of postmenopausal patients treated with either anastrozol alone, or tamoxifen or a combination of both, and observed a similar gain in the 3 groups with a mean of $1,65 \mathrm{~kg}$ over the 24 months of follow-up. Another study ${ }^{13}$ showed a gain of $1,76 \pm 0.66 \mathrm{~kg}$ in postmenopausal women treated with aromatase inhibitor as well as in those who were not treated with aromatase inhibitor over 24 months. Heideman's team ${ }^{26}$ evidenced a mean weight gain of 2,6 $\pm 6 \mathrm{~kg}$ in patients treat combined systemic treatment (chemotherapy + endocrine therapy) one year post diagnosis. We showed that weight loss during chemotherapy (T0-T1) and a high initial fat mass percentage were the strongest parameters associated with the weight gain during endocrine therapy. This is in accordance with a recent review, which highlights that weight gain in the first two years of endocrine therapy is associated with weight loss between diagnosis and the beginning of endocrine therapy ${ }^{17}$.

In our study, this weight gain during endocrine therapy corresponds to an increase in fat mass mainly located in the abdominal region and an increase in lean body mass mostly corresponding to body water. Concerning lean body mass, in the study by Battisti and al., ${ }^{20}$ patients treated with aromatase inhibitor showed an increase in lean body mass and in the lean body mass/fat mass ratio. Similar results were found in a double-blind, placebocontrolled randomized trial, with 24 months follow-up. Only a gain in lean body mass was observed, and no changes in body fat mass were reported in the group of patients treated with aromatase inhibitors compared to those who were not ${ }^{13}$. The authors explain that this lean body mass gain can be induced by the inhibition of aromatase, leading to an accumulation of androgens that are known to be linked to muscle protein synthesis. Nevertheless, both of these studies evaluated body composition only from DXA and did not perform bioelectrical impedance analysis, so that no conclusions were drawn on body water. Our study shows that the gain is mainly due to an increase in intracellular water retention. In addition, as previously described by Battisti and colleagues ${ }^{20}$, variation in abdominal fat mass distribution is observed in women under aromatase inhibitor treatment, and particularly an increase in visceral adipose tissue (i.e. contained in the abdominal cavity). With a followup of around 4 years after initiation of endocrine therapy, the authors observed an increase in total abdominal adipose tissue of $9.1 \%$, which is equal to the increase in total fat mass percentage observed in the present study after endocrine therapy initiation (T2-T3). Nevertheless, we found a greater increase than in this study (17.5\%) over 36 months followup.

During endocrine therapy, weight loss during chemotherapy, initial fat mass class and increase in the time spent sitting after diagnosis are the main parameters associated with fat mass gain. It has been shown that treatments exacerbate the decrease in physical activity ${ }^{27-}$ 
${ }^{29}$ and increase time spent sitting ${ }^{30}$. However, the literature reports that more than the half of the patients are insufficiently active at the time of diagnosis ${ }^{29,31}$. In our study, after a median time of three years post initiation of endocrine therapy (T3), we found that the majority of the population had a level of physical activity of over 750 MET.min/week. International recommendations for physical activity advise 150 minutes/week of moderate activity (3 to 6 MET/week) i.e. between 450 and 750 MET.min/week ${ }^{32}$. These recommendations have been extended to breast cancer patients ${ }^{33-35}$ and many studies have shown the benefits for patients of staying active during treatment, in particular in reducing the risk of death and relapse ${ }^{36}$. Furthermore, being active is of particular interest in reducing fat mass and improving muscle strength ${ }^{37-39}$. It is also important to underline that reducing sitting time is associated with a decrease in mortality ${ }^{40-43}$. More precisely, it has been shown that the replacement of one hour sitting by one hour standing per day significantly reduces mortality ${ }^{43}$. Currently, it is really important to establish physical activity programmes during treatment to encourage patients to comply with international recommendations, particularly in the subpopulation that we have identified. Indeed, as demonstrated in our study, patients with a high initial fat mass percentage are the most exposed to weight variation in the course of treatment, and especially to fat mass gain in the long term, which accumulates predominantly in the trunk region suggesting accumulation of visceral adipose tissue which is associated with cardio-metabolic complications ${ }^{6,20,44}$.

Several studies ${ }^{26-28}$ have described a weight gain in the year following diagnosis, but none according to the sequence of treatment. On the over period of evaluation in this study (from the initiation of chemotherapy to the 3 years of endocrine treatment i.e. 3 years and 6 months of follow-up), we observed a weight gain of $2.0 \mathrm{~kg}$ and this gain was principally due to the weight gain during endocrine therapy. In our study, we did not find any weight gain during the first 9 months after adjuvant treatment initiation in our MetaCa cohort (NCT01506466) (T0T2: from initiation of chemotherapy to 6 months after the end). The weight gain occurred later i.e. during endocrine therapy, and corresponds to a fat mass gain. Endocrine therapy appears to be a pivotal period to explain weight change during endocrine therapy.

Several studies have highlighted that weight variations, either gains or losses, during chemotherapy are implicated in poorer prognosis ${ }^{5,27,45,46}$. The mechanisms of a pejorative impact of weight gain could be explained by the fat mass gain, but for weight loss, they are not clear. Our study shows fat mass gain consecutive to a weight loss during the chemotherapy period. We can hypothesise that losing weight during chemotherapy is associated with a gain in fat mass during endocrine therapy more particularly for patients with fat mass excess (overfat/obese). Previous weight loss could be linked to the later gain through fat overshooting as previously reported in energy restriction ${ }^{47}$. Remarkably, during 
endocrine therapy, we observed a gain in fat mass particularly in the trunk region. Abdominal fat mass excess is well known to be associated with poor prognosis for breast cancer patients ${ }^{48-50}$. One of the mechanisms explaining this relationship is that visceral adipose tissue is associated with metabolic syndrome ${ }^{20}$ and with insulin resistance ${ }^{6,44}$. There is a need to conduct long-term studies on a larger population to explore this hypothesis.

\section{CONCLUSION}

The effects of adjuvant endocrine therapy on body composition among postmenopausal breast cancer survivors were studied in this trial. With three-year hindsight after endocrine therapy initiation, a fairly small weight gain is observed but it is associated with changes in body composition distribution. Indeed, patients gain in fat mass particularly in the trunk region. Overfat/obese patients and those who lost weight during chemotherapy were more subject to weight and fat mass gain during endocrine therapy.

\section{CLINICAL PRACTICE POINTS}

- While several studies have described weight and body composition variation during chemotherapy for early breast cancer, to the best of our knowledge, ours is the first longitudinal study conducted on a cohort of postmenopausal patients treated with chemotherapy, radiotherapy and endocrine therapy.

- Only a fairly small weight gain is observed with a follow-up of 3.6 years post chemotherapy, but it corresponds to the weight gain observed during the endocrine therapy period.

- Overfat/obese patients are more susceptible to a fat mass gain during endocrine therapy than normal fat mass patients. This highlights the interest of nutritional and physical activity interventions focusing also in reducing time spent sitting in this population at the beginning of treatment.

- $\quad$ Further longitudinal cohort studies are needed to confirm these results.

\section{REFERENCES}

1. Reeves GK, Pirie K, Beral V, et al. Cancer incidence and mortality in relation to body mass index in the Million Women Study: cohort study. BMJ. 2007;335(7630):1134. doi:10.1136/bmj.39367.495995.AE

2. Carmichael AR. Obesity and prognosis of breast cancer. Obes Rev Off $J$ Int Assoc Study Obes. 2006;7(4):333-340. doi:10.1111/j.1467-789X.2006.00261.x 
3. Kroenke $\mathrm{CH}$, Chen WY, Rosner B, Holmes MD. Weight, weight gain, and survival after breast cancer diagnosis. J Clin Oncol Off J Am Soc Clin Oncol. 2005;23(7):1370-1378. doi:10.1200/JCO.2005.01.079

4. Caan BJ, Kwan ML, Hartzell G, et al. Pre-diagnosis body mass index, post-diagnosis weight change, and prognosis among women with early stage breast cancer. Cancer Causes Control CCC. 2008;19(10):1319-1328. doi:10.1007/s10552-008-9203-0

5. Thivat E, Thérondel S, Lapirot $\mathrm{O}$, et al. Weight change during chemotherapy changes the prognosis in non metastatic breast cancer for the worse. BMC Cancer. 2010;10:648. doi:10.1186/1471-2407-10-648

6. Gadéa E, Thivat E, Planchat E, Morio B, Durando X. Importance of metabolic changes induced by chemotherapy on prognosis of early-stage breast cancer patients: a review of potential mechanisms. Obes Rev Off J Int Assoc Study Obes. 2012;13(4):368-380. doi:10.1111/j.1467-789X.2011.00957.x

7. Rose DP, Komninou D, Stephenson GD. Obesity, adipocytokines, and insulin resistance in breast cancer. Obes Rev. 2004;5(3):153-165. doi:10.1111/j.1467789X.2004.00142.x

8. Key TJ, Verkasalo PK, Banks E. Epidemiology of breast cancer. Lancet Oncol. 2001;2(3):133-140. doi:10.1016/S1470-2045(00)00254-0

9. Coombes RC, Hall E, Gibson LJ, et al. A randomized trial of exemestane after two to three years of tamoxifen therapy in postmenopausal women with primary breast cancer. N Engl J Med. 2004;350(11):1081-1092. doi:10.1056/NEJMoa040331

10. Goble S, Bear HD. Emerging role of taxanes in adjuvant and neoadjuvant therapy for breast cancer: the potential and the questions. Surg Clin North Am. 2003;83(4):943971. doi:10.1016/S0039-6109(03)00071-9

11. Chaudhary LN, Wen S, Xiao J, Swisher AK, Kurian S, Abraham J. Weight change associated with third-generation adjuvant chemotherapy in breast cancer patients. $J$ Community Support Oncol. 2014;12(10):355-360. doi:10.12788/jcso.0078

12. Jeon YW, Lim ST, Choi HJ, Suh YJ. Weight change and its impact on prognosis after adjuvant TAC (docetaxel-doxorubicin-cyclophosphamide) chemotherapy in Korean women with node-positive breast cancer. Med Oncol Northwood Lond Engl. 2014;31(3):849. doi:10.1007/s12032-014-0849-z

13. van Londen GJ, Perera S, Vujevich K, et al. The impact of an aromatase inhibitor on body composition and gonadal hormone levels in women with breast cancer. Breast Cancer Res Treat. 2011;125(2):441-446. doi:10.1007/s10549-010-1223-2

14. Sestak I, Harvie M, Howell A, Forbes JF, Dowsett M, Cuzick J. Weight change associated with anastrozole and tamoxifen treatment in postmenopausal women with or at high risk of developing breast cancer. Breast Cancer Res Treat. 2012;134(2):727734. doi:10.1007/s10549-012-2085-6

15. Akyol M, Demir L, Alacacioglu A, et al. The Effects of Adjuvant Endocrine Treatment on Serum Leptin, Serum Adiponectin and Body Composition in Patients with Breast Cancer: The Izmir Oncology Group (IZOG) Study. Chemotherapy. 2016;61(2):57-64. doi:10.1159/000440944 
16. Irwin ML, McTiernan A, Baumgartner RN, et al. Changes in body fat and weight after a breast cancer diagnosis: influence of demographic, prognostic, and lifestyle factors. $J$ Clin Oncol Off J Am Soc Clin Oncol. 2005;23(4):774-782. doi:10.1200/JCO.2005.04.036

17. Nyrop KA, Deal AM, Lee JT, et al. Weight changes in postmenopausal breast cancer survivors over 2 years of endocrine therapy: a retrospective chart review. Breast Cancer Res Treat. February 2017. doi:10.1007/s10549-017-4106-y

18. Francini $G$, Petrioli $R$, Montagnani $A$, et al. Exemestane after tamoxifen as adjuvant hormonal therapy in postmenopausal women with breast cancer: effects on body composition and lipids. Br J Cancer. 2006;95(2):153-158. doi:10.1038/sj.bjc.6603258

19. Montagnani A, Gonnelli S, Cadirni A, et al. The effects on lipid serum levels of a 2-year adjuvant treatment with exemestane after tamoxifen in postmenopausal women with early breast cancer. Eur J Intern Med. 2008;19(8):592-597. doi:10.1016/j.ejim.2007.05.016

20. Battisti S, Guida FM, Coppa F, et al. Modification of abdominal fat distribution after aromatase inhibitor therapy in breast cancer patients visualized using 3-D computed tomography volumetry. Clin Breast Cancer. 2014;14(5):365-370. doi:10.1016/j.clbc.2014.02.003

21. Craig CL, Marshall AL, Sjöström M, et al. International physical activity questionnaire: 12-country reliability and validity. Med Sci Sports Exerc. 2003;35(8):1381-1395. doi:10.1249/01.MSS.0000078924.61453.FB

22. The Hospital Anxiety and Depression Scale - Zigmond - 1983 - Acta Psychiatrica Scandinavica - Wiley Online Library. http://onlinelibrary.wiley.com/doi/10.1111/j.16000447.1983.tb09716.x/full. Accessed December 4, 2017.

23. Kwiatkowski F, Girard M, Hacene K, Berlie J. Sem : un outil de gestion informatique et statistique adapté à la recherche en cancérologie. Bull Cancer (Paris). 2000;87(10):715-721.

24. Gallagher D, Heymsfield SB, Heo M, Jebb SA, Murgatroyd PR, Sakamoto Y. Healthy percentage body fat ranges: an approach for developing guidelines based on body mass index. Am J Clin Nutr. 2000;72(3):694-701.

25. Baum M, Budzar AU, Cuzick J, et al. Anastrozole alone or in combination with tamoxifen versus tamoxifen alone for adjuvant treatment of postmenopausal women with early breast cancer: first results of the ATAC randomised trial. Lancet Lond Engl. 2002;359(9324):2131-2139.

26. Heideman WH, Russell NS, Gundy C, Rookus MA, Voskuil DW. The frequency, magnitude and timing of post-diagnosis body weight gain in Dutch breast cancer survivors. Eur J Cancer Oxf Engl 1990. 2009;45(1):119-126. doi:10.1016/j.ejca.2008.09.003

27. Goodwin PJ, Ennis M, Pritchard KI, et al. Adjuvant treatment and onset of menopause predict weight gain after breast cancer diagnosis. $J$ Clin Oncol Off J Am Soc Clin Oncol. 1999;17(1):120-129. doi:10.1200/JCO.1999.17.1.120

28. Rock CL, Flatt SW, Newman V, et al. Factors associated with weight gain in women after diagnosis of breast cancer. Women's Healthy Eating and Living Study Group. J Am Diet Assoc. 1999;99(10):1212-1221. 
29. Gjerset GM, Fosså SD, Courneya KS, Skovlund E, Thorsen L. Exercise behavior in cancer survivors and associated factors. J Cancer Surviv Res Pract. 2011;5(1):35-43. doi:10.1007/s11764-010-0148-4

30. Foucaut A-M, Berthouze SE, Touillaud M, et al. Deterioration of Physical Activity Level and Metabolic Risk Factors After Early-Stage Breast Cancer Diagnosis. Cancer Nurs. 2015;38(4):E1-9. doi:10.1097/NCC.0000000000000187

31. Harrison S, Hayes SC, Newman B. Level of physical activity and characteristics associated with change following breast cancer diagnosis and treatment. Psychooncology. 2009;18(4):387-394. doi:10.1002/pon.1504

32. Ainsworth BE, Haskell WL, Whitt MC, et al. Compendium of physical activities: an update of activity codes and MET intensities. Med Sci Sports Exerc. 2000;32(9 Suppl):S498-504.

33. Objectif 8: Réduire les risques de séquelles et de second cancer - Les 17 objectifs du Plan | Institut National Du Cancer. http://www.e-cancer.fr/Plan-cancer/Plan-cancer2014-2019-priorites-et-objectifs/Les-17-objectifs-du-Plan2/Objectif-8-Reduire-lesrisques-de-sequelles-et-de-second-cancer. Accessed May 26, 2016.

34. Rock CL, Doyle C, Demark-Wahnefried W, et al. Nutrition and physical activity guidelines for cancer survivors. CA Cancer J Clin. 2012;62(4):243-274. doi:10.3322/caac.21142

35. Doyle C, Kushi LH, Byers T, et al. Nutrition and physical activity during and after cancer treatment: an American Cancer Society guide for informed choices. CA Cancer J Clin. 2006;56(6):323-353.

36. Ibrahim EM, Al-Homaidh A. Physical activity and survival after breast cancer diagnosis: meta-analysis of published studies. Med Oncol. 2010;28(3):753-765. doi:10.1007/s12032-010-9536-x

37. Grabenbauer A, Grabenbauer AJ, Lengenfelder R, Grabenbauer GG, Distel LV. Feasibility of a 12-month-exercise intervention during and after radiation and chemotherapy in cancer patients: impact on quality of life, peak oxygen consumption, and body composition. Radiat Oncol Lond Engl. 2016;11:42. doi:10.1186/s13014-0160619-5

38. Kim JJ, Shin YA, Suk MH. Effect of a 12-week walking exercise program on body composition and immune cell count in patients with breast cancer who are undergoing chemotherapy. $J$ Exerc Nutr Biochem. 2015;19(3):255-262. doi:10.5717/jenb.2015.15092812

39. Zhu G, Zhang X, Wang $Y$, Xiong $H$, Zhao $Y$, Sun $F$. Effects of exercise intervention in breast cancer survivors: a meta-analysis of 33 randomized controlled trails. OncoTargets Ther. 2016;9:2153-2168. doi:10.2147/OTT.S97864

40. Fassier $P$, Zelek $L$, Partula $V$, et al. Variations of physical activity and sedentary behavior between before and after cancer diagnosis: Results from the prospective population-based NutriNet-Santé cohort. Medicine (Baltimore). 2016;95(40):e4629. doi:10.1097/MD.0000000000004629 
41. Hu FB, Willett WC, Li T, Stampfer MJ, Colditz GA, Manson JE. Adiposity as compared with physical activity in predicting mortality among women. $N$ Engl $J$ Med. 2004;351(26):2694-2703. doi:10.1056/NEJMoa042135

42. Moore SC, Patel AV, Matthews CE, et al. Leisure time physical activity of moderate to vigorous intensity and mortality: a large pooled cohort analysis. PLoS Med. 2012;9(11):e1001335. doi:10.1371/journal.pmed.1001335

43. Matthews CE, Moore SC, Sampson J, et al. Mortality Benefits for Replacing Sitting Time with Different Physical Activities. Med Sci Sports Exerc. 2015;47(9):1833-1840. doi:10.1249/MSS.0000000000000621

44. Vázquez-Vela MEF, Torres N, Tovar AR. White adipose tissue as endocrine organ and its role in obesity. Arch Med Res. 2008;39(8):715-728. doi:10.1016/j.arcmed.2008.09.005

45. Marret $\mathrm{H}$, Perrotin $\mathrm{F}$, Bougnoux $\mathrm{P}$, et al. Low body mass index is an independent predictive factor of local recurrence after conservative treatment for breast cancer. Breast Cancer Res Treat. 2001;66(1):17-23.

46. Nichols HB, Trentham-Dietz A, Egan KM, et al. Body mass index before and after breast cancer diagnosis: associations with all-cause, breast cancer, and cardiovascular disease mortality. Cancer Epidemiol Biomark Prev Publ Am Assoc Cancer Res Cosponsored Am Soc Prev Oncol. 2009;18(5):1403-1409. doi:10.1158/1055-9965.EPI08-1094

47. Dulloo AG, Jacquet J, Miles-Chan JL, Schutz Y. Passive and active roles of fat-free mass in the control of energy intake and body composition regulation. Eur J Clin Nutr. 2017;71(3):353-357. doi:10.1038/ejcn.2016.256

48. Harvie M, Hooper L, Howell $\mathrm{AH}$. Central obesity and breast cancer risk: a systematic review. Obes Rev. 2003;4(3):157-173. doi:10.1046/j.1467-789X.2003.00108.x

49. Ogundiran TO, Huo D, Adenipekun A, et al. Body fat distribution and breast cancer risk: findings from the Nigerian breast cancer study. Cancer Causes Control CCC. 2012;23(4):565-574. doi:10.1007/s10552-012-9916-y

50. Han D, Nie J, Bonner MR, et al. Lifetime adult weight gain, central adiposity, and the risk of pre- and postmenopausal breast cancer in the Western New York exposures and breast cancer study. Int J Cancer. 2006;119(12):2931-2937. doi:10.1002/ijc.22236 


\section{TABLES CAPTIONS}

Table 1: Characteristics of patients

Abbreviations: $\mathrm{BMI}=$ body mass index; $\mathrm{FEC}=5$ fluorouracile, epirubicin and cyclophosphamide

Table 2: Body composition variations

Weight variation was defined by a gain or loss greater than $5 \%$ of initial body weight. T0-T3 covers the entire period of the study, from pre-adjuvant treatment to a median follow up of 44 months including endocrine therapy. T2-T3 corresponds to a period of 34 months. Endocrine therapy was started on average 3 months before the T2 measurement point. SD: standard deviation; Bold values correspond to $p<0,05$.

\section{FIGURES CAPTIONS}

Figure 1: Flow chart

Six patients from the previous study, MetaCa, are not currently treated with endocrine therapy and three had no DXA measures at T0 or T2, and/or they did not meet selection criteria. Of the forty-three potential inclusions, nine patients refused to participate in the study and one patient had a cardiac device that prevented the DXA measure, corresponding to a non-inclusion criterion.

Figure 2: Study design

All patients were included in the MétaCa2 trial on the occasion of a follow-up visit for their endocrine therapy treatment. All the measurements performed at T3 had already been performed at T0, T1 and T2 (MétaCa trial). RTX: Radiotherapy; DEXA: Dual-energy Xray absorptiometry; IPAQ: International physical activity questionnaire; HAD: Hospital anxiety and depression scale

Figure 3: Percentage of weight variation according to initial fat mass percentage groups

Overfat/Obese patients exhibited more weight changes across the different periods in the study than normal fat mass patients. The difference between the curves is significant $(p=$ $0.033)$ but no time effect is evidenced $(p=0.07)$. 
Figure 4: Body composition variations between T2 and T3

Only the subgroup of overweight/obese patients exhibited statistically significant variations in body composition in the trunk region compared to the healthy subgroup. *Statistically significant $(p<0,05)$. Mean \pm SEM.

\section{TABLES}

\section{Table 1}

\section{General characteristics}

Age at T3 (years), median

Mean weight at T3 $(\mathrm{kg})$

Mean BMI at T3 $\left(\mathrm{kg} / \mathrm{m}^{2}\right), \mathrm{n}(\%)$

$$
\begin{aligned}
B M I & <25 \\
25 \leq B M I & <30 \\
B M I & \geq 30
\end{aligned}
$$

Age at menopause (years), median [min; max]

Initial fat mass percentage (T0), n (\%)

$$
\begin{array}{r}
\text { Normal fat mass : }<36 \% \\
\text { Overfat/Obese }: \geq 36 \%
\end{array}
$$

\section{$64[55 ; 75]$}

$$
70 \pm 15
$$

$26,9 \pm 6,4$

$16(49)$

$8(30)$

$9(21)$

$51[45 ; 59]$

$16(48,5)$

$17(51,5)$

\section{Tumor characteristics}

$\mathrm{pT}, \mathrm{n}(\%)$

$\begin{array}{cc}\text { T1 } & 24(72,7) \\ \text { T2 } & 8(24,2) \\ \text { T3 } & 1(3)\end{array}$

$\mathrm{pN}, \mathrm{n}(\%)$

$\begin{array}{cc}\text { No } & 20(60,6) \\ \text { N1 } & 10(30,3) \\ \text { N2 } & 2(6,1) \\ \text { N3 } & 1(3,0)\end{array}$


Oestrogen receptor, n (\%)

$$
\begin{array}{cr}
\text { positive } & 33(100) \\
\text { negative } & 0(0)
\end{array}
$$

Progesterone receptor, n (\%)

$$
\begin{aligned}
& \text { positive } \\
& \text { negative }
\end{aligned}
$$

HER2 status, n (\%)

$$
\begin{array}{cc}
\text { positive } & 4(12,1) \\
\text { negative } & 29(87,9)
\end{array}
$$

SBR grade, $n(\%)$

$\begin{array}{ll}\text { II } & 21(63,6) \\ \text { III } & 8(24,2) \\ \text { IV } & 4(12,1)\end{array}$

Multifocal tumor, n (\%)

$$
\begin{array}{cc}
\text { yes } & 9(27,3) \\
\text { no } & 24(72,7)
\end{array}
$$

Type of cancer, n (\%)

$$
\begin{array}{rc}
\text { ductal invasive carcinoma } & 24(72,7) \\
\text { lobular invasive carcinoma } & 8(24,2) \\
\text { micro papillary carcinoma } & 1(3)
\end{array}
$$

\section{Treatment characteristics}

Surgery, n (\%)

$$
\begin{array}{rr}
\text { mastectomy } & 10(30,3) \\
\text { conservative surgery } & 23(69,7)
\end{array}
$$

Axillary node dissection, $\mathrm{n}(\%)$

$\begin{array}{cr}\text { yes } & 13(39,4) \\ \text { no } & 20(60,6)\end{array}$

Chemotherapy, n (\%) 


$$
\begin{array}{rc}
3 \text { FEC }+3 \text { docetaxel } & 31(94) \\
6 \text { docetaxel }+ \text { cyclophosphamide } & 2(6)
\end{array}
$$

Type of endocrine therapy at T3

$\begin{array}{rc}\text { Letrozol } & 15(45,5) \\ \text { Anastrozol } & 13(39,4) \\ \text { Exemestane } & 4(12,1) \\ \text { Tamoxifen } & 1(3)\end{array}$

Median duration of endocrine therapy (years) [min; $\quad 3,1 \pm 0,6[1,81 ; 4 ; 51]$ $\max ]$ 
Table 2

\begin{tabular}{|c|c|c|c|c|c|c|}
\hline \multirow{3}{*}{ Body Composition } & \multicolumn{6}{|c|}{ Period } \\
\hline & \multicolumn{3}{|c|}{ T0 - T3 } & \multicolumn{3}{|c|}{ T2 - T3 } \\
\hline & mean & $S D$ & $p$ & mean & $S D$ & $p$ \\
\hline \multicolumn{7}{|l|}{ Weight (Kg) } \\
\hline Overall population $(n=33)$ & 2,0 & 5,4 & 0,031 & 2,0 & 5,5 & 0,04 \\
\hline Normal fat mass $(n=16)$ & 1,5 & 4,7 & 0,22 & 0,06 & 4,8 & 0,96 \\
\hline Overfat/obese $(n=17)$ & 2,5 & 5,9 & 0,094 & 3,8 & 5,6 & 0,012 \\
\hline \multicolumn{7}{|l|}{ Waist circumference (cm) } \\
\hline Overall population $(\mathrm{n}=29)$ & 4,8 & 8 & 0,0032 & 3,3 & 8 & 0,021 \\
\hline Normal fat mass $(n=15)$ & 1,3 & 6,4 & 0,45 & $-0,66$ & 6,1 & 0,68 \\
\hline Overfat/obese $(n=14)$ & 8,5 & 7,8 & 0,0013 & 7,5 & 7,5 & 0,0017 \\
\hline \multicolumn{7}{|l|}{ Total Fat Mass (Kg, DEXA) } \\
\hline Overall population $(n=33)$ & 0,9 & 3,8 & 0,17 & 1,78 & 3,8 & 0,0073 \\
\hline Normal fat mass $(n=16)$ & 1,0 & 3,9 & 0,32 & 0,74 & 3,7 & 0,45 \\
\hline Overfat/obese $(n=17)$ & 0,8 & 3,7 & 0,38 & 2,8 & 3,5 & 0,0054 \\
\hline \multicolumn{7}{|l|}{ Trunk Fat Mass (Kg, DEXA) } \\
\hline Overall population $(n=33)$ & 0,7 & 2,2 & 0,063 & 1,4 & 2,2 & 0,00031 \\
\hline Normal fat mass $(n=16)$ & 0,6 & 2,1 & 0,27 & 0,6 & 2 & 0,27 \\
\hline Overfat/obese $(n=17)$ & 0,8 & 2,2 & 0,16 & 2,2 & 2 & 0,00067 \\
\hline \multicolumn{7}{|c|}{ Total Lean Body Mass (Kg, DEXA) } \\
\hline Overall population $(n=33)$ & 1,5 & 3,2 & 0,0083 & 0,8 & 2 & 0,035 \\
\hline Normal fat mass $(n=16)$ & 0,9 & 2,5 & 0,18 & 0,2 & 1,9 & 0,63 \\
\hline Overfat/obese $(n=17)$ & 2.1 & 3,7 & 0,034 & 1,4 & 2,2 & 0,024 \\
\hline \multicolumn{7}{|c|}{ Trunk Lean Body Mass (Kg, DEXA) } \\
\hline Overall population $(n=33)$ & 0,9 & 2 & 0,015 & 0,75 & 1,6 & 0,01 \\
\hline Normal fat mass $(n=16)$ & 0,4 & 1,5 & 0,3 & 0,1 & 1,4 & 0,69 \\
\hline Overfat/obese $(n=17)$ & 1,3 & 2,3 & 0,034 & 1,4 & 1,6 & 0,0048 \\
\hline \multicolumn{7}{|c|}{ Total Body Water (Kg, Impedance) } \\
\hline Overall population $(n=29)$ & 0,8 & 2,5 & 0,082 & 0,8 & 2 & 0,036 \\
\hline Normal fat mass $(n=15)$ & 1,0 & 2,2 & 0,11 & 0,3 & 2,3 & 0,65 \\
\hline Overfat/obese $(n=14)$ & 1,6 & 2,7 & 0,39 & 1,4 & 1,6 & 0,0052 \\
\hline \multicolumn{7}{|c|}{ Bone mineral content (g, DEXA) } \\
\hline Overall population $(n=31)$ & 1,0 & 4,5 & 0,2 & 1,1 & 4,6 & 0,19 \\
\hline Normal fat mass $(n=15)$ & 0,96 & 4,3 & 0,39 & 0,97 & 4,3 & 0,39 \\
\hline Overfat/obese $(n=17)$ & 1,1 & 4,7 & 0,37 & 1,2 & 4,9 & 0,36 \\
\hline
\end{tabular}




\section{FIGURES}

\section{Fiqure 1}

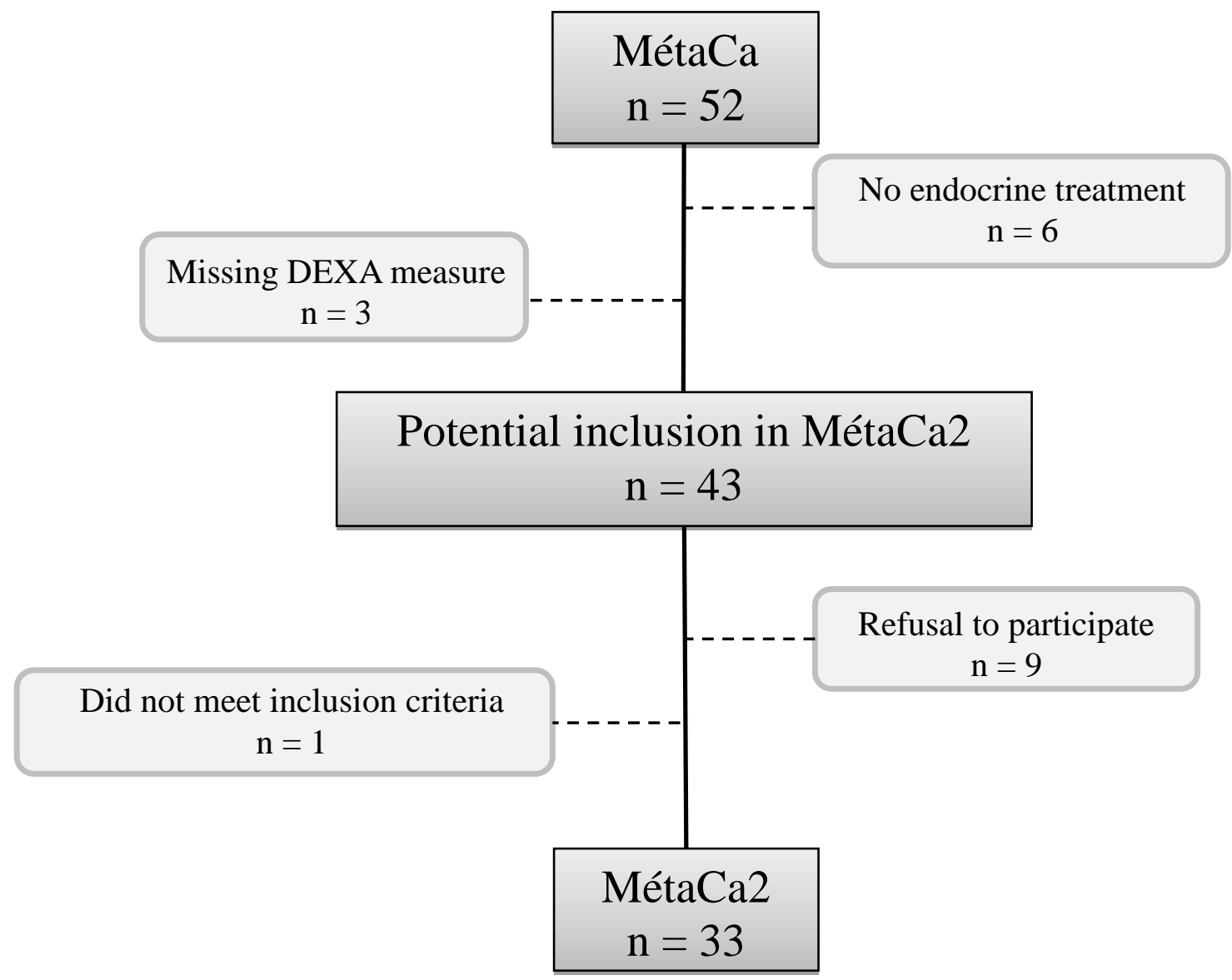

\section{Figure 2}

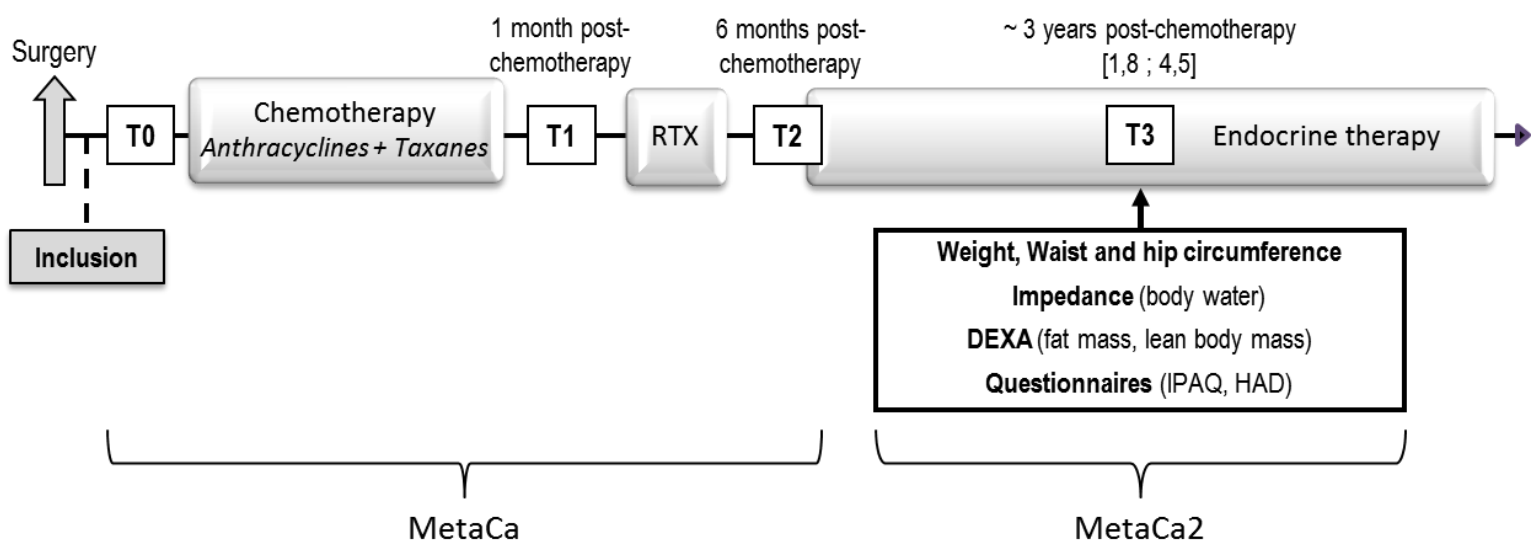




\section{Figure 3}

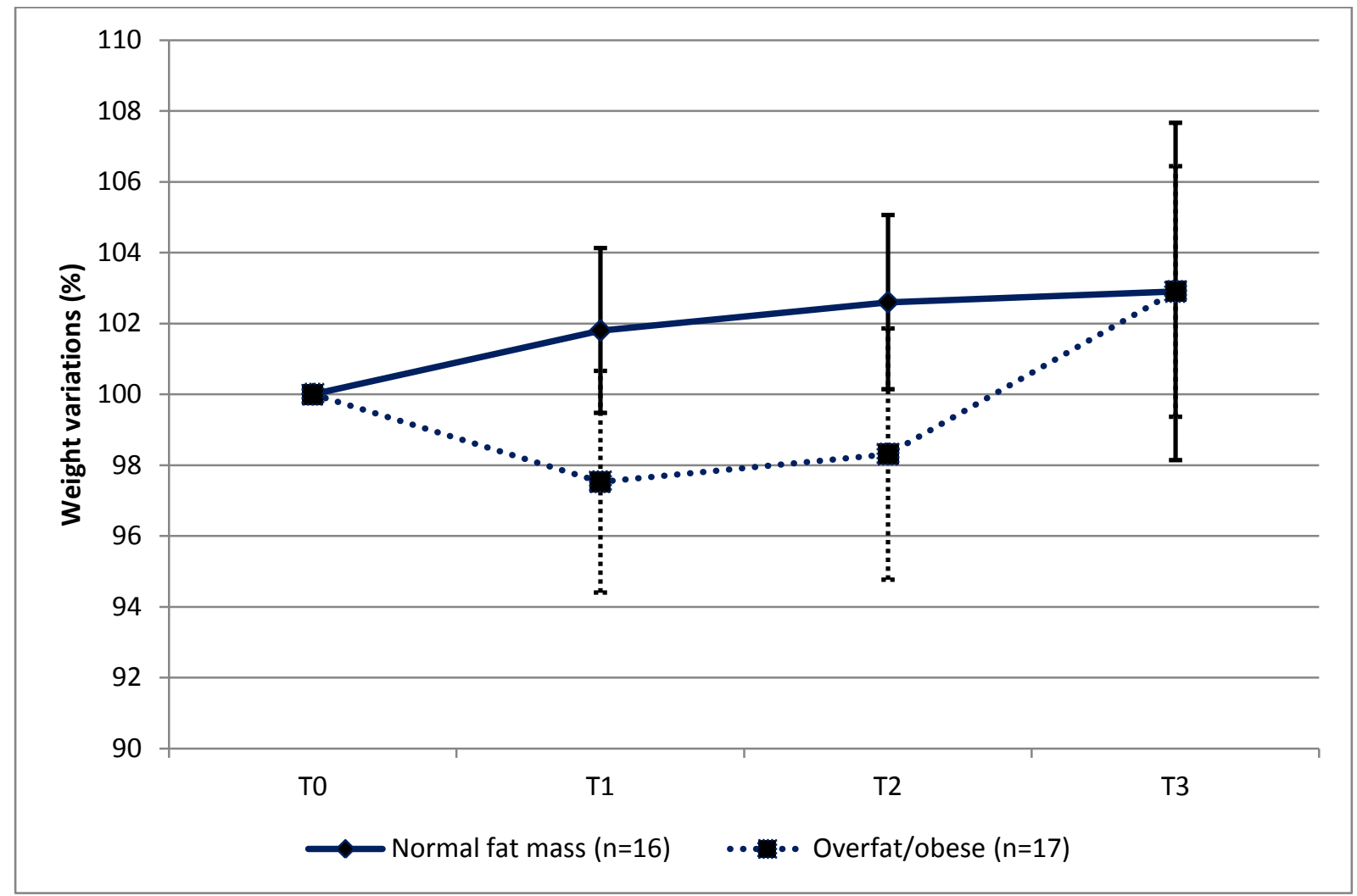


Figure 4

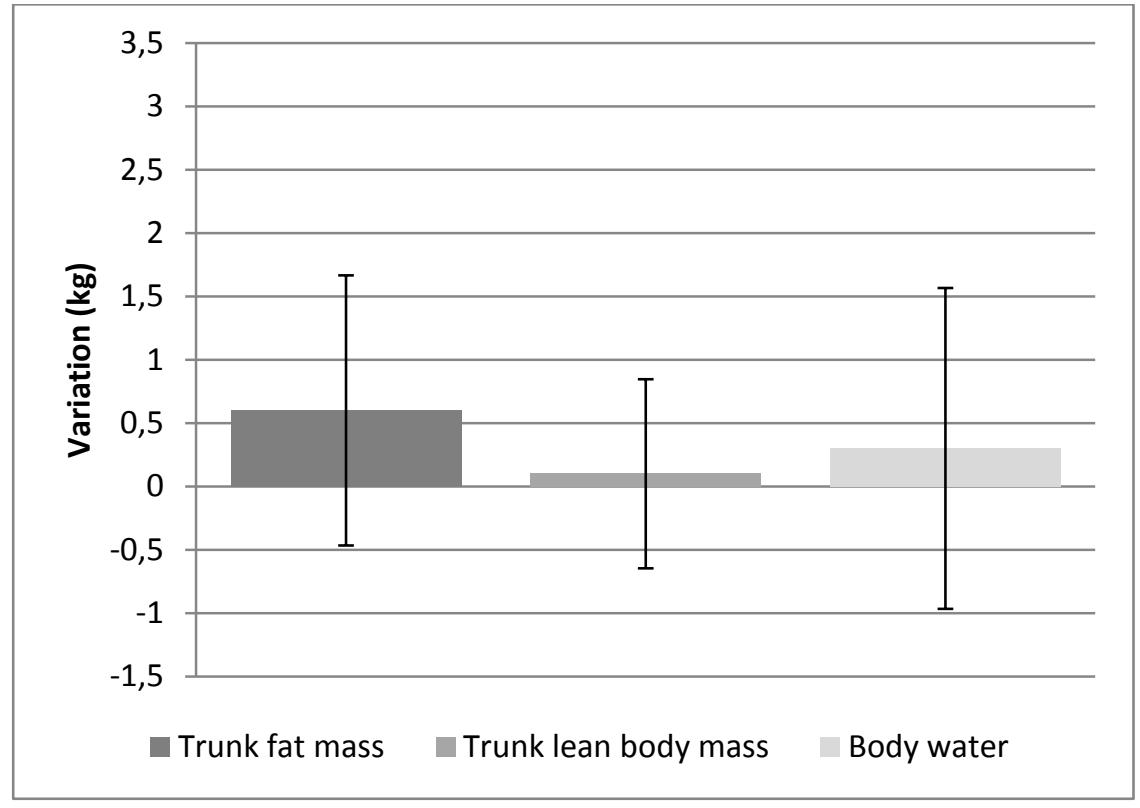

a. Body composition of normal fat mass subgroup ( $\mathrm{N}=16)$

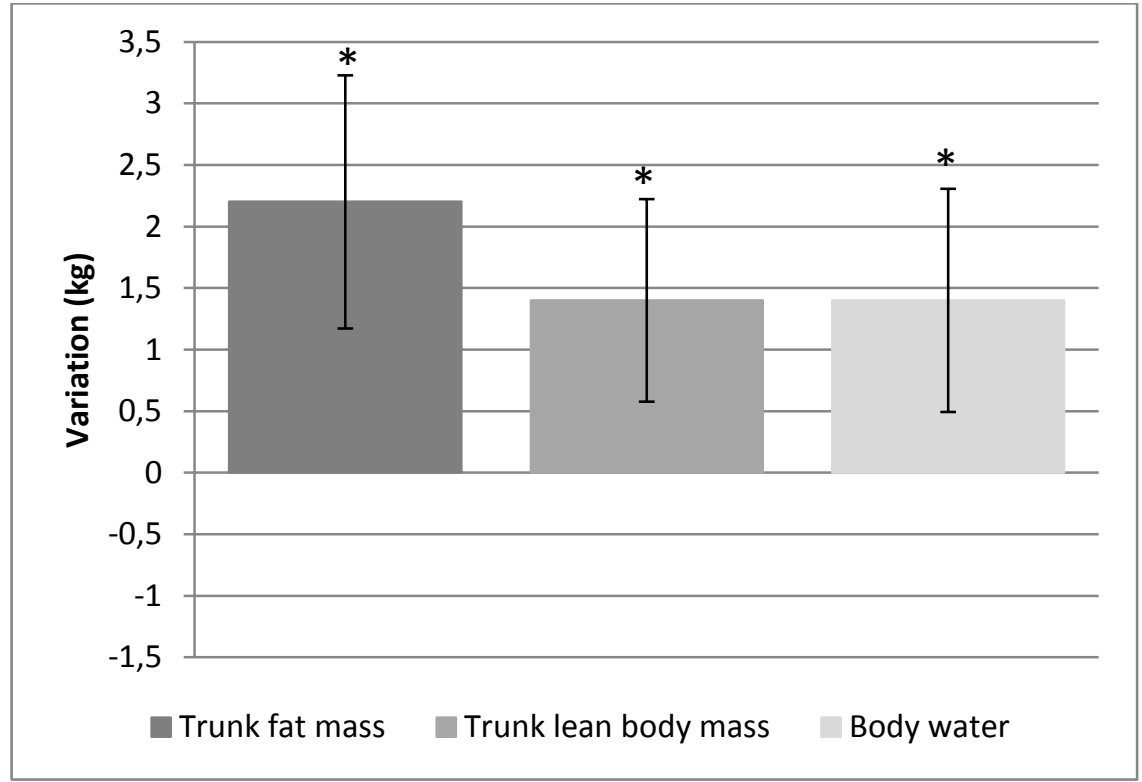

b. Body composition of overfat/obese subgroup $(\mathrm{N}=17)$ 